\title{
Corona losses: issues and solutions
}

\begin{abstract}
As the demand for power increases, reduction of undesired energy during the transmission and distribution of electrical energy becomes a vital issue. In this respect corona will play an important role in the near future. Loss of energy due to corona is governed by both power line properties and environmental factors. In order to address corona related issues, electrical designers should have a good knowledge on corona generation and the effects of corona under various conditions. Methods developed during the last many decades to minimize corona effects, have their own advantages and disadvantages. This study discusses in detail these methods with the view of providing information to develop new methodologies to overcome the drawbacks of present corona prevention techniques.
\end{abstract}

Keyword: Corona; Loss of energy; Power electric systems 